\title{
Las disputas por la Jurisdicción Especial para la Paz (JEP): una reflexión crítica sobre su sentido político y jurídico*
}

The Disputes for the Special Jurisdiction for Peace (JEP): A Critical Reflection on its Political and Legal Meaning

\author{
Gabriel Ignacio Gómez a \\ Universidad de Antioquia, Colombia \\ gomez.gabrielignacio@gmail.com \\ ORCID: https://orcid.org/0000-0002-6219-4117
}

DOI: https://doi.org/10.11144/Javeriana.vj69.djep

Recepción: 07 Octubre 2019

Aceptación: 20 Noviembre 2019

Publicación: 30 Junio 2020

\section{Resumen:}

Este artículo busca hacer una caracterización de la Jurisdicción Especial para la Paz (JEP) en Colombia desde una perspectiva sociopolítica y sociojurídica crítica. De acuerdo con esta perspectiva, la justicia transicional conlleva una profunda relación entre la política y el derecho, de manera que el análisis que se haga sobre una institución como la JEP debe tener en cuenta el contexto, las construcciones discursivas y las tensiones políticas que inciden en su configuración. El artículo se basa en un trabajo de investigación fundamentalmente bibliográfico y documental en el que se examina, además de la literatura especializada, información de prensa, documentación institucional e informes sobre el tema. El artículo, en primer lugar, da cuenta del contexto sociopolítico que dio lugar a la creación de la JEP; posteriormente, describe las principales discusiones y disputas políticas y jurídicas por transformar la JEP; y concluye con un análisis en el que se destaca la tensión entre una orientación retributivista de carácter selectivo, especialmente por parte de quienes han tenido una postura de oposición al Acuerdo Final, y una perspectiva holista, liderada por quienes han defendido las bondades de una paz negociada.

Palabras clave: Justicia Transicional, Jurisdicción Especial para la Paz, Proceso de Paz, Colombia.

\section{Abstract:}

This article aims to characterize the Special Jurisdiction for Peace (JEP) in Colombia from a critical sociopolitical and sociolegal perspective. According to this approach, the field of transitional justice implies an intertwined relationship between politics and law. In consequence, the analysis of the JEP should comprehend the context, the discursive constructions, and the political disputes that frame it. The article is based on archival research methods that included academic references, institutional reports, news media information, and other documents on the matter. The first part of the article presents an account of the sociopolitical context that made possible designing the JEP. Subsequently, it describes the main political and legal disputes to transform the JEP. The article finally provides an analysis that highlights the contradiction between a selective retributivist approach, mainly sustained by those who have opposed the Peace Agreement, and a holistic perspective, led by those who have supported the advantages of a negotiated peace.

Keywords: Transitional Justice, Special Jurisdiction for Peace, Peace Process, Colombia.

\section{Introducción}

Uno de los componentes del Acuerdo de Paz entre el Gobierno Nacional y las antiguas FARC-EP, que mayores debates ha generado durante los últimos años en Colombia, ha sido el relacionado con los mecanismos de justicia transicional y, más específicamente, la Jurisdicción Especial para la Paz (JEP). Durante más de tres años, la sociedad colombiana ha estado expuesta a discusiones políticas y jurídicas sobre la constitucionalidad, conveniencia y legitimidad de estos mecanismos. Este artículo busca hacer una caracterización del sentido político y jurídico de la JEP. Para tal efecto, se parte de una perspectiva sociojurídica crítica de acuerdo con la cual se entiende la justicia transicional como un campo social ${ }^{[1]}$, y como tal, se le concibe como un espacio de interrelación entre el derecho y la política en el que múltiples actores,

Notas de autor

a Autor de correspondencia. Correo electrónico: gomez.gabrielignacio@gmail.com 
con diversos discursos, intereses, y niveles de poder, se disputan la apropiación de sentidos sobre la forma de entender y transformar los conflictos políticos, de pensar la justicia y los derechos de las víctimas. En tal sentido, la justicia transicional y los mecanismos institucionales y sociales que se diseñan no necesariamente son expresiones de homogeneidad social, sino, más bien, de tensiones entre estos actores y discursos, y en los cuales el sentido sobre el derecho, la justicia y las instituciones jurídicas, son objeto de disputa.

En un sentido más general sobre las relaciones entre la sociedad y el derecho, la perspectiva propuesta se distancia tanto de las aproximaciones normativistas o institucionalistas, que hacen ver al derecho como un creador de la realidad social, como de las orientaciones estructuralistas que conciben el derecho como un resultado de las dinámicas económicas y políticas. Más bien, el derecho y las instituciones jurídicas, son tanto expresiones de las dinámicas sociales como creadoras y transformadoras de las mismas ${ }^{[2]}$.

En un sentido más específico, cuando abordamos el campo de la justicia transicional, estamos en un escenario mucho más complejo aún, pues nos encontramos una zona de intersección bastante intensa entre la política y el derecho. Vale la pena retomar la reflexión de Ruti Teitel ${ }^{[3]}$, quien, al hacer referencia a las relaciones entre el derecho y la política en la justicia transicional, mostraba una tensión entre dos orientaciones. Por un lado, una tendencia realista en donde la política se superpone sobre el derecho, de manera que este se constituye en una expresión de las relaciones de poder; y por el otro, una tendencia liberal en sentido filosófico, que ella denomina idealista, según la cual el derecho está llamado a limitar el poder. Teitel llama la atención sobre la insuficiencia de estas dos concepciones para explicar las relaciones entre el derecho y la política en los contextos transicionales. Por un lado, porque la mirada realista desconoce la relevancia de la dimensión ética y jurídica, y por el otro, porque la perspectiva idealista se desentiende de los contextos y las relaciones de poder existentes. Por tal razón, Teitel adopta una concepción constructivista de acuerdo con la cual se reconoce al derecho como resultado de un contexto, pero, a su vez, se resaltan las posibilidades transformadoras de las instituciones jurídicas.

En consecuencia, no basta preguntarse por la naturaleza jurídica de la institución, es necesario también comprender las condiciones sociales que han definido su significación política y jurídica, así como el potencial transformador que ella ofrece en una sociedad afectada por un conflicto tan prolongado y destructivo. Teniendo claro este punto de partida teórico, pasaré entonces a mencionar algunos aspectos iniciales sobre el contexto específico del caso colombiano. La creación del Sistema Integral de Verdad, Justicia, Reparación y No Repetición (SIVJRNR), representó un punto de llegada bastante relevante en el proceso de negociación entre los actores políticos. El punto quinto del Acuerdo Final (AF) se constituyó en el componente más complejo y delicado de la negociación, y por tal razón, el que más tiempo demandó ${ }^{[4]}$. Como parte de este acuerdo se creó un conjunto de instituciones de justicia transicional que comprende a la Unidad de Búsqueda de Personas Dadas por Desaparecidas (UBPD), la Comisión de Esclarecimiento de la Verdad (CEV), la Jurisdicción Especial para la Paz (JEP), y los mecanismos de reparación. Así mismo, entre los negociadores se acordó que los mecanismos de justicia transicional debían partir del principio de la centralidad de las víctimas y, en tal sentido, que estas instituciones debían velar por el efectivo desarrollo de los derechos de las víctimas del conflicto armado ${ }^{[5]}$.

Con posterioridad a la firma del AF, sobrevinieron diferentes debates en la sociedad colombiana sobre el punto quinto del acuerdo y, específicamente, sobre la JEP. Estos desacuerdos se dejaron ver con notoriedad durante 2016, en momentos previos al plebiscito; se retomaron con ocasión de la revisión del AF y la refrendación congresional, continuaron en el periodo de implementación en el Congreso de la Republica en 2017, fueron uno de los temas cruciales en la campaña presidencial del 2018 y volvieron a tomar fuerza en 2019 con ocasión de las objeciones presidenciales a la Ley Estatutaria de la JEP. Estos han sido debates fundamentalmente políticos, que aún hoy están lejos de estar totalmente resueltos, pero que tienen repercusiones jurídicas e institucionales. En tal sentido, el diseño e implementación de la JEP se desarrollan en medio de la tensión que se da principalmente entre dos tendencias discursivas relativamente identificables, sin que ello desconozca matices o posturas intermedias. Por un lado, una perspectiva construida con base en el AF, 
que, desde una perspectiva holista, defiende las bondades de una paz negociada y el diseño de mecanismos de justicia transicional, a pesar de que este pueda ser imperfecto. por el otro lado, una tendencia que, en términos generales, ha sido adversa a la negociación política, al AF, y que considera que los mecanismos diseñados otorgaron muchas concesiones a las FARC en detrimento de otros sectores sociales e institucionales.

Con el fin de exponer estas tensiones y sus implicaciones, este artículo, inicialmente, ofrece elementos de contexto que permiten comprender mejor los diferentes intereses y perspectivas en disputa. Posteriormente, da cuenta de la manera en que se han dado los diferentes debates políticos y jurídicos sobre la JEP. Finalmente, el artículo propone un análisis teniendo en cuenta tres categorías: el sentido social y político de la JEP, la concepción de justicia que está en juego, y la naturaleza jurídica de este tribunal. La definición de esta tensión por el diseño e implementación de la JEP tiene, y tendrá, consecuencias con respecto al funcionamiento de este tribunal y al desarrollo efectivo de los derechos de las víctimas. La descripción y el análisis expuesto se basan en un trabajo de investigación documental que ha implicado el seguimiento de prensa sobre los debates más significativos alrededor de los mecanismos de justicia transicional en Colombia, así como el estudio de documentos oficiales expedidos por el gobierno nacional, debates en el Congreso, sentencias de las cortes y reportes de organizaciones e instituciones que han hecho seguimiento al proceso de paz.

\section{Contexto: El diseño de la JEP resultado de una negociación política}

En cuanto al contexto colombiano, hay que recordar varios aspectos. En primer lugar, el colombiano es un caso bastante especial América Latina. No es propiamente una experiencia de transición de dictadura a democracia, como lo fueron los casos de Argentina, Chile, Uruguay o Brasil; ni es una transición de la guerra a la paz como lo fueron los casos de El Salvador y Guatemala en las décadas del noventa ${ }^{[6]}$. Se trata de un caso complejo de transiciones parciales de conflicto armado hacia la paz, aún pendiente por resolver totalmente ${ }^{[7]}$, y que ha tenido diferentes momentos y expresiones institucionales.

Un primer momento tiene que ver con la desmovilización de los grupos paramilitares entre 2003 y 2006, y el conjunto de mecanismos que surgieron con ocasión de dicha desmovilización. Como resultado de estas negociaciones se expidió la ley 975 de 2005 (Ley de Justicia y Paz), mediante la cual se creó la Jurisdicción de Justicia y $\mathrm{Paz}^{[8]}$. Un segundo momento se dio entre 2007 y 2011, y consistió en la movilización de las organizaciones de derechos humanos y de las redes de apoyo a las víctimas para promover un marco jurídico en favor de las víctimas. Esta movilización terminaría por crear las condiciones de posibilidad para que se expidiera la ley 1448 de 2011, más conocida como ley de Víctimas y Restitución de Tierras ${ }^{[9]}$.

Un tercer momento, bastante complejo y en el cual se relaciona este artículo, corresponde al proceso de paz entre el Gobierno Nacional y las FARC. Se trata de una negociación política bastante larga y difícil que, luego de cuatro años de conversaciones, logró un acuerdo de paz con la guerrilla más antigua del continente y dio fin a un ciclo de violencias que se había iniciado desde la década del sesenta. Como parte de los acuerdos, se diseñó el Sistema Integral de Verdad Justicia y Reparación y No Repetición (SIVJRNR) ${ }^{[10]}$.

Así, el punto quinto del AF fue el resultado de una intensa y compleja negociación política entre quienes, aceptando la existencia de un conflicto armado, tenían posturas diferentes sobre la justicia. Ello implicó acercar la visión más maximalista que tenían los negociadores del gobierno Santos ${ }^{[11]}$, de acuerdo con la cual era necesaria la existencia de tribunales que procesaran y sancionaran con pena de prisión efectiva a los máximos responsables de graves violaciones de derechos humanos y crímenes de guerra, tal como lo establecía el Marco Jurídico para la $\mathrm{Paz}^{[12]}$; y una perspectiva minimalista defendida por los negociadores de las FARC, que buscaba amnistías y mecanismos de justicia restaurativa ${ }^{[13]}$. Finalmente, luego de muchas discusiones, y con base en el apoyo de la Comisión de Asesores designada por los negociadores, se llegó a una propuesta que combinaba principios de justicia restaurativa y de justicia retributiva ${ }^{[14]}$. De acuerdo 
con esta propuesta, quienes hubieran participado en crímenes de guerra o graves violaciones de derechos humanos, debían comprometerse seriamente en el reconocimiento de los hechos, en el esclarecimiento de la verdad y en la contribución a la reparación. Si cumplían con tales condiciones, recibirían sanciones de carácter restaurativo. De lo contrario, recibirían sanciones de orden retributivo ${ }^{[15]}$.

\section{Las luchas en el proceso de refrendación}

El hecho de que se llegara a un acuerdo sobre los mecanismos de justicia transicional en la mesa de conversaciones en La Habana, no implicaba que en el escenario político nacional existiera el mismo nivel de consenso. Según Francisco de Roux ${ }^{[16]}$, en la mesa de conversaciones hubo un proceso de transformación de los diferentes actores que les permitió llegar a un acuerdo en beneficio de las víctimas y del país. Sin embargo, agrega de Roux, ese proceso de transformación no se vio, ni se vivió de igual manera en la sociedad colombiana. Por el contrario, el carácter reservado de las negociaciones, así como la falta de una pedagogía social sobre el proceso de paz, permitieron que, durante esos años, la especulación y la construcción del miedo por parte de los opositores del proceso de paz fueran generando una disposición adversa en varios sectores sociales.

Los defensores del $\mathrm{AF}^{[17]}$, si bien reconocían que había aspectos que se podían mejorar, o incluso con asuntos que no compartían, en general insistían en la necesidad de entenderlo como un conjunto de disposiciones orientadas a promover la paz. De otra parte, los diferentes sectores de oposición al $\mathrm{AF}^{[18]}$, con respecto al componente de justicia, fundamentaban su postura en los siguientes enunciados discursivos: en primer lugar, la negación de la existencia del conflicto armado y, en consecuencia, el cuestionamiento de un proceso de paz negociada; en segundo lugar, el rechazo al SIVJRNR en su conjunto, y a la JEP en particular, por considerar que esta era un mecanismo de impunidad, puesto que no contemplaba como sanción principal la pena privativa de la libertad; y en tercer lugar, el rechazo a la posibilidad de que los comandantes de las FARC asumieran cargos de representación política en el Congreso sin que rindieran cuentas ante los tribunales.

En efecto, uno de los aspectos que más preocupación generaba por parte de quienes se oponían al proceso tenía que ver con la creación de la JEP y la perspectiva de justicia que en ella subyacía. Un ejemplo ilustrativo de la construcción de este discurso lo representan las opiniones de Álvaro Uribe sobre el contenido del acuerdo referente a la JEP. Según Uribe, el acuerdo:

ignora que en Colombia ha habido una acción narcoterrorista contra la democracia, a diferencia de otras partes de América Latina donde insurgencias civiles armadas enfrentaron dictaduras, lo cual mereció el calificativo de conflicto. Nuestras Fuerzas Armadas no han sido de la dictadura, todo lo contrario, se distinguen por su respeto a la democracia. [19]

Después de la firma del Acuerdo de Septiembre ${ }^{[20]}$, la tensión política se incrementó en la sociedad colombiana en los momentos previos a la refrendación del AF a través del plebiscito programado para el 2 de octubre. Más que un ejercicio racional de democracia deliberativa ${ }^{[21]}$, el ambiente político y social se polarizó y exacerbó pasiones en dos direcciones diferentes. El gobierno Santos y los promotores del proceso de paz buscaban legitimar el proceso mediante estrategias que buscaban explicar los contenidos de los acuerdos y crear mensajes que apelaban a la esperanza. A su vez, los opositores del proceso de paz desplegaron estrategias mediáticas que apelaban a sentimientos de indignación social, como, por ejemplo, afirmar que el AF era "un pacto de impunidad", o que Colombia sería "otra Venezuela" ${ }^{[22]}$. El resultado más tangible de esta exacerbación de la pasión política y de la polarización social fue el resultado del plebiscito, cuando en las urnas el NO (con 50,23\% de los votos), se impuso sobre el SI (con un 49,76\%) por un estrecho margen ${ }^{\text {[23] }}$ . Días después del plebiscito se sabría que la estrategia de los promotores del NO, consistió en promover 
sentimientos de enojo en la opinión pública, tal como lo admitiera Juan Carlos Vélez, entonces gerente de la campaña por el NO, en una entrevista con el diario La República ${ }^{[24]}$.

En este escenario, el gobierno Santos se reunió con los líderes del NO, quienes presentaron 68 propuestas de modificación al AF ${ }^{[25]}$. Muy pronto, lo que fue evidentemente un resultado sorpresivo, trató de ser reencuadrado por el gobierno y los movimientos por la paz como la oportunidad para consolidar un mejor acuerdo. Múltiples organizaciones sociales comenzaron a movilizarse en todo el territorio nacional solicitando un ;Acuerdo $Y a !^{[26]}$. Si bien hubo aspectos que no se podían reformar sin alterar cuestiones medulares de los acuerdos, se buscaron hacer ajustes que permitieran hacer precisiones que dieran tranquilidad a quienes tenían temores o posturas escépticas ${ }^{[27]}$.

Con respecto al tema de la JEP, se hicieron varios ajustes que precisaban o aclaraban asuntos que habían sido objeto de discusión por parte de los promotores del NO, como los relacionados con los conflictos de competencias con la jurisdicción ordinaria, los plazos de funcionamiento de la JEP, el alcance de la contribución a la verdad, los marcos jurídicos aplicables, la presunción de legalidad de la actuación de agentes estatales, los delitos conexos con el delito político, la responsabilidad de mando, la acción de tutela contra decisiones de la JEP, y la composición del tribunal de paz y de las diferentes salas y secciones, entre otros ${ }^{[28]}$. No obstante, para los negociadores era imposible ceder frente a dos asuntos supremamente sensibles: la imposición de penas privativas de la libertad, y la eliminación de la representación política ${ }^{[29]}$. Luego de llegar a un nuevo Acuerdo, se procedió a firmarlo a los pocos días, en una ceremonia que tuvo lugar en el Teatro Colón de Bogotá el 24 de noviembre de 2016, y a refrendarlo ante el Congreso de la República.

\section{Las disputas políticas por la implementación en el Congreso (2017-2018)}

Con posterioridad a la refrendación, le correspondió al Congreso de la República desarrollar el marco normativo para la implementación del AF. De acuerdo con lo pactado, en el Acto Legislativo 01 de 2016 se creó un mecanismo más expedito, conocido como fast track, que simplificaba los trámites de los Actos Legislativos y de las leyes ${ }^{[30]}$. Este mecanismo simplificado buscaba evitar que el proceso de paz fracasara por la dilación en la implementación, tal como había ocurrido en otras experiencias internacionales. Por tal razón, se previó un periodo inicial de seis meses para la aplicación del fast track. Sin embargo, debido a la lentitud de los debates en el Congreso, se tuvo que prorrogar por otros seis meses ${ }^{[31]}$. Si bien para 2017 el Gobierno Santos contaba con el apoyo de las mayorías en el Congreso, el ambiente político en este escenario no fue suficientemente favorable para tramitar de manera expedita los proyectos previstos en la implementación del AF. De acuerdo con el Observatorio de Seguimiento a la Implementación del Acuerdo de Paz (OIAP), en ese periodo el Congreso solamente logró tramitar diez de los veinticuatro proyectos presentados por el Gobierno Nacional ${ }^{[32]}$.

Efectivamente, durante el periodo de 2017 y 2018 emergió un nuevo escenario de debate político que habría de someter a la JEP a nuevos intentos de transformación. En principio, las mayorías del Congreso conformadas por la coalición de Gobierno, conocida como la Unidad Nacional ${ }^{[33]}$, apoyaban el proceso de paz y su implementación. Sin embargo, diferentes tensiones políticas incidieron para que aflorara con más fuerza la contradicción entre los opositores del AF, quienes sostenían que habían sido traicionados por el gobierno Santos luego del plebiscito, y los defensores de los acuerdos, quienes consideraban que era imperativo implementar el AF. Además, el ambiente electoral previo a las elecciones presidenciales de 2018 comenzaba a erosionar el nivel de apoyo de los partidos que anteriormente habían respaldado las políticas de paz del gobierno de Santos.

Esta tensión se dejaría ver en el proceso de implementación y en el diseño normativo que se dio entre marzo y abril de 2017, cuando se expidió el Acto legislativo 01 que constitucionalizó el AF y creó la JEP. En el 
segundo semestre de 2017, la tensión política se intensificó con ocasión de la selección de los Magistrados de la JEP, y del trámite del proyecto de Ley Estatutaria de la JEP (LEJEP). Posteriormente, en 2018, cuando se tramitó el proyecto de Ley de Procedimiento de la JEP, el escenario del Congreso se constituyó nuevamente en un escenario de disputa política que tenía como telón de fondo la contienda por la presidencia.

\section{Aspectos específicos de mayor debate}

La estrategia de modificar la JEP, tal como fue concebida, llevó entonces a que se promovieran reformas, entre otros aspectos, sobre los siguientes puntos: la composición e inhabilidades de los magistrados, la comparecencia de terceros y agentes estatales, el tratamiento a los miembros de la fuerza pública, y las competencias de la JEP para evaluar pruebas en casos de solicitud de extradición de personas procesadas ante este tribunal. Veamos estos aspectos con mayor detenimiento.

\section{Composición de la JEP e Inhabilidades de los magistrados}

Según el AF y el Acto Legislativo 01 de 2017, un Comité de Escogencia se encargaría de la designación de los miembros de las diferentes instituciones creadas (CEV, UBPD y JEP), mediante un proceso transparente y público ${ }^{[34]}$. Desde un principio, el Comité de Escogencia y las personas seleccionadas fueron cuestionadas por parte de quienes hacían oposición al proceso de paz y al AF. El Centro Democrático ya había lanzado una serie de ataques a la forma de composición de la JEP, a la participación de expertos internacionales y al nombramiento de los magistrados ${ }^{[35]}$. Por su parte, Cambio Radical, en su comunicado de septiembre de 2017, manifestó que "la mayoría de los recién nombrados magistrados tienen una clara tendencia política que, de entrada, no generan (sic) ninguna clase de garantías para la sociedad civil..." ${ }^{[36]}$.

Para el momento en que se debatió el proyecto de LEJEP en el Senado, este partido propuso incluir nuevas inhabilidades a los magistrados escogidos. Se estableció que las personas que durante los últimos cinco años hubieran litigado en contra de los intereses del Estado o hubieran representado a grupos de derechos humanos, no podrían hacer parte de este sistema de justicia transicional. De inmediato, las organizaciones de derechos humanos cuestionaron estas críticas y reivindicaron la trayectoria de los magistrados seleccionados, así como la dignidad de los defensores de derechos humanos ${ }^{[37]}$. Al respecto, la Comisión Interamericana de Derechos Humanos en su informe de 2017 sostuvo que "de aprobarse una Ley Estatutaria que contenga dicha limitante, ésta podría constituir un obstáculo para la defensa de los derechos humanos y los derechos de las víctimas en el marco de la JEP" [38] . A pesar de las advertencias y objeciones por parte de las organizaciones sociales y de la comunidad internacional, estas inhabilidades quedaron incluidas en el proyecto de LEJEP ${ }^{[39]}$.

\section{Participación de terceros, agentes estatales y militares}

Otro de los aspectos frente a los que mostraban su rechazo los partidos Centro Democrático y Cambio Radical tenía que ver con que personas civiles fueran convocadas a comparecer ante la JEP. Según lo establecido en el AF, la JEP debía ser competente para juzgar tanto a los combatientes como a aquellos civiles que habían contribuido a promover acciones que se constituían en violaciones a los derechos humanos o graves infracciones al DIH. Esta participación de civiles no era una novedad, por el contrario, se trataba de un asunto bastante documentado ${ }^{[40]}$. El Centro Democrático lideró una fuerte oposición a la JEP en el Congreso con base en la idea de que esta era "un mecanismo de impunidad" creado a la medida de los "deseos de venganza de las FARC y que buscaba usarse en contra de los civiles y de los agentes estatales" [41] 
. Por su parte, Cambio Radical sostenía que tenía el deber de "proteger a todos los sectores productivos y en particular a los ciudadanos que han invertido en el campo colombiano y fueron víctimas del conflicto, que hoy pueden ser revictimizados por un tribunal que no les ofrecerá garantías jurídicas suficientes" [42]. Como consecuencia de la presión de estas fuerzas políticas, el Congreso estableció en el proyecto de LEJEP que los terceros solamente acudirían a la JEP de manera voluntaria. Este debate volvió a aparecer en la discusión del proyecto de ley de procedimiento de la JEP. En este caso, el Centro Democrático propuso modificar en el último debate el proyecto existente con el fin de introducir en la estructura de la JEP una sala especial que juzgara a los miembros de las fuerzas armadas ${ }^{[43]}$.

\section{Competencia de la JEP para evaluar pruebas frente a solicitudes de extradición}

Un acontecimiento que habría de generar otro intenso debate político fue la captura con fines de extradición del exnegociador de las FARC, Jesús Santrich, por parte de la Fiscalía General de la Nación, el 9 de abril de $2018^{[44]}$. Por una parte, sectores críticos del AF y de la JEP veían que la captura de Santrich demostraba que este había continuado con acciones delictivas y argumentaban que la Corte Suprema debería autorizar pronto su extradición ${ }^{[45]}$. Por otra parte, los miembros del partido FARC consideraban que se trataba de un montaje y que no había garantías jurídicas para los desmovilizados ${ }^{[46]}$. En todo caso, quienes defendían el proceso de paz y la autonomía de la JEP sostenían que había que esclarecer los hechos y agotar los procedimientos propios de un Estado de Derecho, incluyendo la posibilidad de evaluar las pruebas en que se fundamentaba la solicitud. La JEP, por su parte, optó por solicitar las pruebas que sustentaban la solicitud de extradición ${ }^{[47]}$.

Debido a que estos acontecimientos se dieron antes de la discusión del proyecto de Ley de procedimiento de la JEP, los debates después dejaron ver las posturas políticas y jurídicas en uno y otro sentido. El Centro Democrático propuso incluir dentro del proyecto de ley la restricción a la JEP para evaluar las pruebas en caso de solicitudes de extradición ${ }^{[48]}$. De otro lado, quienes sospechaban del uso político de la extradición y del efecto negativo que podría tener en el proceso de paz, argumentaban que la extradición no era una obligación y que debía ajustarse a los límites establecidos por el ordenamiento jurídico colombiano. Entre esos límites, estaba la posibilidad de examinar las pruebas sobre las cuales se basaba la solicitud de extradición ${ }^{[49]}$.

\section{Tensiones en la Corte Constitucional}

El debate se trasladó de un escenario político bastante polarizado a un espacio que requería de un escrutinio racional más exigente y en donde las reglas de juego implicaban mayor argumentación jurídica. Según lo dispuesto en el Acto Legislativo 01 de 2016, a la Corte Constitucional le correspondía llevar a cabo, por primera vez, el control previo de constitucionalidad de los actos legislativos que introdujeran reformas derivadas de los acuerdos de paz. Igualmente, debía hacer el examen de constitucionalidad del proyecto de la LEJEP en 2018. Más adelante, luego de la expedición de la Ley 1922 de 2018 o ley de procedimiento de la JEP, la Corte asumió también el examen de constitucionalidad de esta ley ante la demanda interpuesta por Dejusticia y la Comisión Colombiana de Juristas ${ }^{[50]}$. Todos estos casos se constituyeron en escenarios de debate sobre los derechos de las víctimas y en la posibilidad de corregir las modificaciones introducidas por el Congreso. A continuación, presentaré los aspectos que más discusión política generaron y la manera como allí se presentaron los debates jurídicos. 


\section{Inhabilidades para ser magistrado de la JEP}

Tal como se había expuesto anteriormente, una de las modificaciones propuestas por el Centro Democrático y Cambio Radical fue la introducción de inhabilidades para ser Magistrados del Tribunal para la Paz y Magistrados de salas a quienes, dentro de los cinco años anteriores, hubieran sido representantes de víctimas de violaciones de derechos humanos en procesos contra el Estado. Múltiples organizaciones nacionales e internacionales intervinieron ante la Corte Constitucional a través de Amicus Curiae y expusieron fundamentalmente dos argumentos. En primer lugar, que las inhabilidades propuestas contravenían normas internacionales vinculantes para el Estado Colombiano, como las contenidas en el Pacto Internacional de Derechos Civiles y Políticos, la Convención Americana sobre Derechos Humanos y los principios básicos sobre la independencia de la judicatura. En segundo lugar, que estas restricciones contradecían el Acto Legislativo 01 de $2017^{[51]}$. Al respecto, la Corte Constitucional en la sentencia C-080 de 2018 decidió que, en efecto, las inhabilidades consagradas en el proyecto de LEJEP eran inconstitucionales por contradecir lo establecido en el Acto Legislativo 01 de $2017^{\text {[52] }}$.

\section{Participación de terceros y de agentes estatales}

Otro aspecto que había generado un fuerte debate político tenía que ver con la participación de terceros en los procesos de la JEP. De acuerdo con los partidos Centro Democrático y Cambio Radical, la JEP sería un instrumento de venganza en contra de sectores empresariales que habían sido víctimas del secuestro y de los actos de las FARC ${ }^{[53]}$. Esta perspectiva de los opositores de la JEP quedó reflejada, entre otras disposiciones, en el parágrafo 4 del artículo 63 del proyecto de LEJEP, que definía la competencia personal. En la versión final del proyecto, los terceros civiles a quienes se les hubiera iniciado una investigación o estuvieran vinculados a un proceso penal, no estaban obligados, sino que podían comparecer ante la JEP dentro de los tres meses siguientes a partir de la entrada en vigencia de la ley ${ }^{[54]}$. Según varias organizaciones de Derechos Humanos que intervinieron ante la Corte Constitucional, como la Comisión Colombiana de Juristas, estas disposiciones desconocían los estándares internacionales sobre la lucha contra la impunidad. Al final, la Corte Constitucional declaró la exequibilidad de esta norma ${ }^{[55]}$. En consecuencia, ni los civiles que hayan participado indirectamente en el conflicto armado (entre los que se encuentran los empresarios financiadores de los grupos armados), ni los agentes del Estado (alcaldes, ministros, funcionarios públicos y gobernadores), ni tampoco los miembros de la Fuerza Pública están obligados a presentarse ante la JEP. Sin embargo, estas personas están obligadas a responder ante la justicia ordinaria.

\section{Tratamiento diferenciado a los miembros de la Fuerza Pública}

Otro aspecto bastante sensible tenía que ver con el tratamiento diferenciado a los miembros de la Fuerza Pública. En su caso, por su condición de agentes estatales, ellos no pueden cometer delitos políticos. Sin embargo, tanto en el AF como en el Acto Legislativo se reconoció que debían ser objeto de un tratamiento diferenciado en la JEP. A pesar del reconocimiento que se hacía de su condición, el Centro Democrático había sostenido públicamente que se trataba de una forma injusta de tratar a los militares ${ }^{[56]}$. Un argumento similar fue expuesto por el representante de ACORE en la audiencia pública convocada por la Corte Constitucional para la discusión sobre la constitucionalidad de la LEJEP ${ }^{[57]}$.

$\mathrm{Al}$ respecto sostiene la Corte Constitucional: 
El tratamiento diferenciado evita que la justicia transicional se convierta en una herramienta de venganza política y, al contrario, promueve el cierre integral del conflicto armado y propicia la reconciliación basada en el fortalecimiento del Estado de Derecho frente a todos los responsables, pero también basada en el ofrecimiento de tratamientos especiales y seguridad jurídica para todos ellos ${ }^{[58]}$.

Aun así, el Centro Democrático insistió en que no era suficiente el trato diferenciado previsto en el Acto Legislativo 01 de 2017 y en la LEJEP. Por tal razón, en los últimos debates del proyecto de ley, proponía en el artículo 75 suspender el trámite de los procesos hasta que se expidiera una ley con un procedimiento especial para los miembros de la fuerza pública. Este artículo fue demandado por varias organizaciones de derechos humanos y declarado inexequible por la Corte Constitucional por violar los principios de consecutividad e identidad flexible que debe tener el trámite legislativo ${ }^{[59]}$.

\section{Prohibición de practicar pruebas frente a solicitudes de extradición}

Finalmente, por iniciativa del Centro Democrático, el proyecto de ley de procedimiento de la JEP en su artículo 54 estableció la prohibición para que la JEP practicara pruebas en casos de solicitud de extradición de uno de los comparecientes o procesados. Esta restricción fue objeto de la demanda constitucional interpuesta por la Comisión Colombiana de Juristas y Dejusticia. Posteriormente, múltiples organizaciones de derechos humanos y facultades de Derecho del país apoyaron los argumentos de los demandantes en intervenciones ante la Corte ${ }^{[60]}$. Finalmente, la Corte Constitucional declaró inconstitucional la restricción de practicar pruebas a la JEP por violar los principios al debido proceso y a la autonomía judicial ${ }^{[61]}$.

\section{El contrataque político: las objeciones presidenciales}

El 10 de marzo de 2019, el presidente Duque se dirigió al país en un mensaje televisivo para anunciar que objetaría parcialmente la LEJEP por motivos de inconveniencia y que, además, presentaría ante el Congreso de la República un conjunto de reformas. En su alocución afirmó que su postura pretendía constituirse en un llamado a la unidad de la sociedad y a superar las separaciones políticas entre los amigos y enemigos del acuerdo de paz ${ }^{[62]}$. Sin embargo, las organizaciones sociales, la oposición al gobierno Duque, los defensores de derechos humanos y múltiples sectores académicos vieron con mucha preocupación estas objeciones. En respuesta a la intervención del presidente, la oposición dejó en claro que lejos de argumentar inconveniencia, las objeciones se sustentaban en argumentos jurídicos sobre asuntos ya definidos por la Corte Constitucional en la sentencia C-080 de 2018 que declaró la constitucionalidad del proyecto de LEJEP ${ }^{\text {[63] }}$.

Este incidente abría un nuevo capítulo en la disputa política por reformar la JEP e incidir políticamente en su alcance normativo e institucional. Lo que siguió fue un intenso debate que continuó con la consulta formulada por el presidente de la Cámara de Representantes a la Corte Constitucional sobre la procedencia de las objeciones, y la subsiguiente respuesta de la Corte declarándose inhibida hasta tanto no se surtieran los debates en el Congreso de la República ${ }^{[64]}$. Luego, ante el rechazo de las objeciones en el Congreso, nuevas presiones se dejaron ver en contra de las cortes. Inicialmente, la Embajada de Estados Unidos revocó las visas de un congresista y varios magistrados ${ }^{[65]}$. Posteriormente, el 15 de mayo, ante la decisión de la JEP de otorgar la garantía de no extradición a Jesús Santrich, y la renuncia de Néstor Humberto Martínez como Fiscal General, el Centro Democrático reiteró los cuestionamientos al proceso de paz y a las cortes [66]. A pesar de la presión política, el 29 de mayo se tomaron dos decisiones muy significativas: 1) la Corte Suprema ordenó nuevamente la libertad de Jesús Santrich ${ }^{[67]}$, quien había sido capturado una vez más y, 2) la Corte Constitucional reconoció que las objeciones presidenciales fueron rechazadas en el Congreso y, en 
consecuencia, el Gobierno debía sancionar la Ley Estatutaria de la JEP ${ }^{[68]}$. Con esta decisión se cerraba, al menos parcialmente, la disputa por definir el marco regulatorio de la JEP.

\section{La Jurisdicción Especial para la Paz: los desafíos por construir la paz}

Luego de exponer las diferentes disputas políticas y jurídicas por la configuración de la JEP, en esta última sección se busca hacer un breve análisis sociojurídico sobre las relaciones entre la política y el derecho en las tensiones observadas con base en tres categorías fundamentales: el sentido social y político de la JEP, la concepción de justicia, y la naturaleza jurídica.

\section{El sentido social y político de la JEP}

Si bien los mecanismos de justicia transicional derivados del proceso de paz con las FARC-EP son la expresión de un acuerdo político que contó con el apoyo de sectores sociales favorables al proceso, no se trató de un consenso generalizado, por el contrario, su sentido social y político ha sido disputado y, en consecuencia, su legitimidad ha sido puesta en cuestionamiento. Para sectores que han defendido el AF y reivindican las ventajas de una paz negociada, el sentido social y político de la JEP está muy vinculado al contexto en el que emergió, es decir, una negociación política en un escenario de un prolongado conflicto armado, y en el que no hubo vencedores ni vencidos. Por su parte, el sector más visible de quienes se han opuesto a los mecanismos del AF, insisten en la negación del conflicto armado, en la construcción del enemigo como terrorista, y en el uso de las instituciones jurídicas en función de las necesidades bélicas. Por tal razón, esta postura tiende a construir imaginarios sociales sobre un enemigo con quien no es posible negociar y a quien solo hay que derrotar, ya sea militar o jurídicamente. Sin embargo, esta tensión, ha generado varios efectos perversos. En primer lugar, la disputa política ha creado una fuerte división en la sociedad colombiana y ha erosionado la confianza en el proceso de paz y, en segundo lugar, ha restado centralidad a las víctimas y obstaculizado la posibilidad de promover acciones y discursos más transformadores hacia el futuro.

\section{Concepciones sobre la justicia}

Esta tensión política se manifiesta entonces en la contradicción entre una forma particular de justicia retributiva que es selectiva en sus destinatarios y termina convirtiendo al derecho en un instrumento de combate en contra de los enemigos y de negociación frente a los amigos; y una concepción holista que busca promover condiciones de construcción de los lazos sociales mediante mecanismos de justicia restaurativa. No obstante, esta contradicción, se desarrolla de manera diferente en los campos político y jurídico. En el campo político, algunos opositores al AF y a la JEP, como se expuso anteriormente, han apelado a estrategias mediáticas de desprestigio y deslegitimación, a dilatar o bloquear el proceso de implementación y, más recientemente, a atacar, no solamente a la JEP, sino a las altas cortes. En el campo jurídico, y concretamente en las cortes, los discursos políticos se han matizado, al menos parcialmente. No obstante, a pesar de que la mayor parte de los debates de constitucionalidad han permitido balancear los principios de justicia, de búsqueda de la paz y avalar a las nuevas instituciones creadas con ocasión del proceso de paz, también resulta problemático el hecho que algunas decisiones, como la relacionada con el carácter potestativo de la comparecencia de terceros civiles ante la JEP, pueda limitar el esclarecimiento de la verdad. 


\section{Naturaleza jurídica y funciones de la Jurisdicción especial para la paz}

Desde una perspectiva realista del derecho, la naturaleza jurídica de la JEP depende, en buena parte, de su entorno social y político, de la orientación política y jurídica que tengan sus magistrados y de las prácticas mismas que pueda desarrollar en el futuro. Por lo pronto, hay un andamiaje jurídico que se ha logrado construir en medio de estas tensiones, pero que ha sido sometido a una intensa disputa por variar los propósitos y contenidos inicialmente propuestos en el AF. Según lo establecido en el AF, así como en el marco normativo internacional y nacional, la JEP es una jurisdicción especial de carácter excepcional y temporal orientada a contribuir fundamentalmente en la transformación del conflicto armado en Colombia. Por tal razón, la JEP no fue diseñada para reproducir en sus decisiones la racionalidad de la jurisdicción ordinaria, sino que obedece a una concepción de justicia transicional desde un carácter holístico y a una perspectiva de justicia fundamentalmente restaurativa.

Por el contrario, los opositores del AF y de la JEP, tal como ha sido diseñada, buscan que este escenario sea fundamentalmente retributivo, o en su defecto, simplemente que no exista. Los debates desarrollados a lo largo del proceso de implementación dan cuenta de un interés por reformar el diseño original de la JEP, introduciendo inhabilidades para sus magistrados, restringiendo el factor de competencia personal de manera que no haya obligación de comparecer de terceros civiles, funcionarios estatales y miembros de la fuerza pública, y restringiendo la posibilidad de aplicar garantías de no extradición a las personas que participaron en el proceso de paz. El resultado de esta disputa política ha causado, además de un ambiente de deslegitimación, que la JEP no haya contado oportunamente con todas las herramientas jurídicas para poder cumplir sus funciones. Esta situación, si bien no impidió que la JEP funcionara, sí implicó que tuviera que acudir a mecanismos de integración e interpretación normativa \#ampliando la discrecionalidad judicial\# para poder desarrollar sus funciones. Finalmente, ahora que la JEP cuenta con las herramientas jurídicas básicas, es necesario construir las condiciones políticas y sociales para que esta institución pueda operar y cumplir adecuadamente las funciones encomendadas.

\section{Conclusiones}

De acuerdo con lo expuesto, no es suficiente con indagar por la naturaleza formal de las instituciones jurídicas, y menos aún en escenarios de transición, sin establecer las relaciones con el contexto social y político en que estas emergen. Por tal razón se dio cuenta de las especificidades del caso colombiano y de la dificultad que ofrece un escenario tan complejo, caracterizado por un conflicto armado de larga duración, en el cual no hay una transición simple de la guerra a la paz, sino un conjunto de transiciones parciales en medio de una conflictividad política que no está resuelta. Este escenario también deja ver el desafío de la sociedad colombiana por construir un proyecto de Estado Social de Derecho. Este desafío es mucho mayor cuando advertimos la dificultad de transformar las heridas y los traumas del pasado, y más bien, los reproducimos a través de la construcción de imaginarios que esencializan al otro mediante del uso de lenguajes de odio y de miedo. En ese escenario de contienda, el derecho y los dispositivos jurídicos pueden constituirse en instrumentos de violencia institucional y simbólica usados para destruir al enemigo en nombre de la justicia; o si somos más cautos, nos pueden abrir las puertas para transformar los relatos de odio y procurar comprendernos en nuestra compleja historia.

Este artículo ha mostrado cómo el andamiaje jurídico sobre el cual se ha construido la JEP, ha estado sometido a intensos debates políticos y jurídicos entre dos tendencias relativamente identificables: de un lado, quienes han defendido la posibilidad una transición negociada y, en consecuencia, el diseño de un conjunto de mecanismos que renuncian a una postura maximalista y, del otro, quienes, al oponerse a la solución negociada, han promovido un proyecto de retributivismo selectivo. Sin embargo, el hecho de que la sociedad colombiana 
lleve más de tres años en esta tensión política ha impedido que se asuman otras discusiones relacionadas con el proyecto de sociedad que se debe construir en el futuro.

Finalmente, si bien la JEP y las normas que la desarrollan son expresión de las tensiones políticas anteriormente descritas, esto no implica que estén totalmente abandonadas a la influencia de las fuerzas políticas. El lenguaje del derecho y la nueva institucionalidad con sus símbolos, su producción argumentativa y sus prácticas, también generan nuevas realidades que pueden orientar la construcción de rutas muy significativas de acción institucional y social. Parte de esta potencialidad y de este desafío consiste precisamente en comenzar a mostrar un proceso dialógico orientado a promover escenarios de justicia restaurativa. Es decir, de participación de las víctimas, así como de escucha y transformación de los victimarios, con el fin de tejer nuevos relatos que satisfagan la necesidad de esclarecer los hechos, de dignificar la memoria de quienes padecieron tanto sufrimiento y de posibilitar la reconstrucción de nuevos proyectos de vida.

\section{Bibliografía}

Acto Legislativo 01 de 2012. Por medio del cual se establecen instrumentos jurídicos de justicia transicional en el marco del artículo 22 de la Constitución Política y se dictan otras disposiciones, 31 de julio de 2012. D. O. No. 48.508.

Acto Legislativo 01 de 2016. por medio del cual se establecen instrumentos jurídicos para facilitar y asegurar la implementación y el desarrollo normativo del Acuerdo Final para la terminación del conflicto y la construcción de una paz estable y duradera, 07 de julio de 2016. D. O. No. 49927.

Acto Legislativo 01 de 2017. Artículo transitorio 7, parágrafo 1. Por medio del cual se crea un título de disposiciones transitorias de la constitución para la terminación del conflicto armado y la construcción de una paz estable y duradera y se dictan otras disposiciones, 4 de abril de 2017. D.O. 50.196.

Acuerdo Final de Paz [Gobierno Nacional y FARC-EP]. Acuerdo final para la terminación del conflicto y la construcción de una paz estable y duradera. 12 de noviembre de 2016. https://www.cancilleria.gov.co/sites/def ault/files/Fotos2016/12.11_1.2016nuevoacuerdofinal.pdf

Cambio Radical, Cambio Radical no votará reglamentación de la Jurisdicción Especial para la Paz (2017). http://www .partidocambioradical.org/wp-content/uploads/2018/09/CR10.pdf

Centro Democrático, "Proyecto de ley estatutaria de JEP es irregular": Centro Democrático, YouTube (12 de noviembre, 2017). https://www.youtube.com/watch?v=rFwkSnR8qxo

Chantal Mouffe, Democracia Politica y pluralismo agónico. Revista Derecho y Humanidades. n. ${ }^{\circ} 12,17-27$ (2006). htt ps://derechoyhumanidades.uchile.cl/index.php/RDH/article/view/16195

Colombia 2020, Listos los magistrados. ¿Qué viene para la JEP?, El Espectador (26 de septiembre, 2017). https://colo mbia2020.elespectador.com/jep/listos-los-magistrados-que-viene-para-la-jep

Colprensa, Gobierno solicita prórroga de aplicación del "fast track", El País (26 de mayo, 2017). https://www.elpais.co $\mathrm{m} . c o /$ proceso-de-paz/gobierno-solicita-prorroga-de-aplicacion-del-fast-track.html

Comisión Colombiana de Juristas, El espejismo de la justicia y la paz. Balance sobre la aplicación de la ley 975 de 2005 (Comisión Colombiana de Juristas, 2008). https://www.peacepalacelibrary.nl/ebooks/files/328547980.pdf

Comisión Interamericana De Derechos Humanos (CIDH), Informe Anual. Capítulo V. Seguimiento de recomendaciones formuladas por la CIDH en sus informes de país o temáticos (2017).

Comité Internacional de la Cruz Roja (CICR), La situación humanitaria se agravó en 2018 (2019). https://www.icrc .org/es/document/la-situacion-humanitaria-en-colombia-se-agravo-en-2018

Corte Constitucional de Colombia. Sentencia C-080 de 2018 (M.P. Antonio José Lizarazo; 15 de agosto de 2018).

Corte Constitucional de Colombia. Sentencia C-112 (M.P. José Fernando Reyes Cuartas; 13 de marzo de 2019).

Dejusticia, Dejusticia y la Comisión Colombiana de Juristas demandan la ley de procedimiento de la JEP (2 de agosto, 2018). https://www.dejusticia.org/dejusticia-y-la-comision-colombiana-de-juristas-demandan-la-ley-de -procedimiento-de-la-jurisdiccion-especial-para-la-paz/ 
Diario La República, Entrevista con Juan Carlos Vélez, YouTube (5 de octubre, 2016). https://www.youtube.com/w atch?v=9Jwuk-fGbrs

Diego Alejandro Martínez, Hacia una ampliación del concepto de justicia. La Jurisdicción Especial para la Paz en Colombia, en La justicia al encuentro de la paz en contextos de transición. Reflexiones actuales para desafíos colombianos (Camilo Eduardo Umaña ed., Universidad Externado de Colombia, 2018).

Elin Skaar, Jemima García-Godos \& Cath Collins, Transitional Justice in Latin America. The uneven road from impunity towards accountability (Routledge, 2016).

Francisco De Roux, La audacia de la paz imperfecta (Editorial Planeta, 2018).

Fundación Ideas para la Paz, Radiografía del plebiscito y el posplebiscito (2016). http://www.ideaspaz.org/especiale s/posplebiscito/

Gabriel Ignacio Gómez, Entre el castigo y la reconciliación. Análisis sociojurídico del proceso de paz y la negociación del Acuerdo sobre las Victimas del Conflicto. Estudios Políticos, n. ${ }^{\circ}$ 50, 236-256 (2017). https://doi.org/10.17533/ udea.espo.n50a13

Gobierno Nacional, Documento de trabajo: cambios, precisiones y ajustes (2016). http://equipopazgobierno.presidencia. gov.co/Documents/cambios-precisiones-ajustes-nuevo-acuerdo-final-terminacion-conflicto-construccion-pazestable-duradera.pdf

Justicia, Capturan por narcotráfico a Jesús Santrich, porpetición de EEUU, El Tiempo ( 9 de abril, 2018). https://www .eltiempo.com/justicia/investigacion/capturan-a-jesus-santrich-lider-de-la-farc-203104

Justicia, Corte decide no pronunciarse sobre las objeciones de Duque a la JEP, El Tiempo (21 de marzo, 2019). https://w ww.eltiempo.com/justicia/cortes/objeciones-a-la-jep-corte-esperara-a-que-el-congreso-se-pronuncie-339874

La Silla Vacía, Goebertus vs. Duque objeciones JEP, YouTube (13 de marzo, 2019). https://www.youtube.com/watch? $\mathrm{v}=\mathrm{h} 1 \mathrm{EToYfLa} 2 \mathrm{w}$

María Isabel Rueda, "Por poco logramos un acuerdo con Álvaro Uribe": Sergio Jaramillo. Entrevista con María Isabel Rueda, El Tiempo (8 de agosto, 2017). https://www.eltiempo.com/politica/proceso-de-paz/entrevista-con-ser gio-jaramillo-sobre-el-acuerdo-de-paz-con-las-farc-117414

Ministerio de Justicia, Congreso aprueba el Proyecto de Ley Estatutaria de la administración de justicia en la Jurisdicción Especial para la Paz (JEP) (30 de noviembre, 2017). https://www.minjusticia.gov.co/Noticias/congreso-aprueba-el-proyecto-de-ley-estatutaria-de-la-admin istraci243n-de-justicia-en-la-jurisdicci243n-especial-para-la-paz-jep-1

Nelson Camilo Sánchez, Leigh Payne, Gabriel Pereira, Laura Bernal, Daniel López \& Miguel Barboza, Cuentas claras. El papel de la Comisión de la Verdad en la develación de la responsabilidad de empresas en el conflicto armado colombiano (Dejusticia, Bogotá, 2018).

Pierre Bourdieu, La Fuerza del Derecho. Elementos para una sociología del campo jurídico (Ediciones Uniandes, Instituto Pensar, Siglo del Hombre Editores, 2001).

Política, Uribismo arremete contra la JEP tras decisión que favorece a Santrich, El Tiempo (15 de mayo, 2019). https://www.eltiempo.com/politica/partidos-politicos/reacciones-politicas-por-decision-de-la-jep-en-e xtradicion-de-santrich-361988

Presidencia de la República de Colombia, Alocución del presidente Iván Duque sobre la Ley Estatutaria de la Jurisdicción Especial para la Paz (2019). https://id.presidencia.gov.co/Paginas/prensa/2019/190310-Alocucion-del-Presid ente-Ivan-Duque-Marquez-sobre-la-Ley-Estatutaria-de-la-Justicia-Especial-Para-La-Paz-JEP.aspx

RCN Radio, Duque advierte que extraditará a Jesús Santrich si delinquió después de proceso de paz (29 de mayo, 2018). https://www.rcnradio.com/politica/duque-advierte-que-extraditara-jesus-santrich-si-delinquio-t ras-acuerdo-de-paz

Redacción EL TIEMPO, Polarización del país reflejada en los resultados del escrutinio, El Tiempo (2 de octubre, 2016). https://www.eltiempo.com/politica/proceso-de-paz/resultados-plebiscito-2016-42861

Redacción Judicial, JEP pide a la Fiscalía expediente completo de Jesús Santrich, El Espectador (18 de septiembre, 2018). https://www.elespectador.com/noticias/judicial/jep-pide-la-fiscalia-expediente-completo-de-jesus-sant rich-articulo- 812867 
Redacción Judicial, La Fiscalía captura a alias "Jesús Santrich", El Espectador (9 de abril, 2018). https://www.elespec tador.com/noticias/judicial/fiscalia-captura-alias-jesus-santrich-articulo-749088

Redacción Política, Acato la decisión de la Corte: Presidente Duque, obligado a sancionar la ley estatutaria de la JEP, El Espectador (29 de mayo, 2019). https://www.elespectador.com/noticias/politica/por-decision-de-la-corte-con stitucional-duque-sancionara-la-estatutaria-de-la-jep-articulo- 863400

Redacción Política, Implementación va en 18.3\%, según el Observatorio de Seguimiento al Acuerdo de Paz, El Espectador (4 de enero, 2018). https://www.elespectador.com/noticias/politica/implementacion-va-en-183-segun-el-obse rvatorio-de-seguimiento-al-acuerdo-de-paz-articulo-731595

Redacción Política, Organizaciones sociales rechazan impedimentos a magistrados de la JEP, El Espectador (16 de noviembre, 2017).

Ricardo Monsalve Gaviria, Uribe arremete contra la Jurisdicción Especial de Paz, El Colombiano (17 de Julio, 2016). https://www.elcolombiano.com/colombia/paz-y-derechos-humanos/uribe-arremete-contra-la-jurisdic cion-especial-de-paz-JM4583391

Rodrigo Uprimny, Extradición, victimas y paz: el caso "Santrich", Dejusticia (5 de mayo, 2018). https://www.dejustic ia.org/column/extradicion-victimas-y-paz-el-caso-santrich/

Rodrigo Uprimny \& Maria Paula Saffon, Reparaciones transformadoras, justicia distributiva y profundización democrática, en Reparar en Colombia: los dilemas en contextos de conflicto, pobreza y exclusión (Catalina Díaz, Camilo Sánchez \& Rodrigo Uprimny, eds., Centro de Estudios de Derecho, Justicia y Sociedad, Dejusticia, 2009).

Ruti G. Teitel, Transnational Justice (Oxford University Press, 2000).

Sandra Botero, El plebiscito y los desafios politicos de consolidar la paz negociada en Colombia. 37 Revista de Ciencia Política, n. ${ }^{\circ}$ 2, 369-388 (2017). https://doi.org/10.4067/s0718-090x2017000200369

Semana, ¿Cómo se cocinó el acuerdo sobre justicia en La Habana? (26 de septiembre, 2015). https://www.semana.com /nacion/articulo/justicia-transicional-el-camino-para-llegar-acuerdo-con-las-farc/443862-3

Semana, Corte Suprema ordena libertad de Jesús Santrich (29 de mayo, 2019). https://www.semana.com/nacion/arti culo/corte-suprema-ordena-libertad-de-jesus-santrich/617436

Semana, Koffi Annan se equivoca, no vamos a pagar ni un día de cárcel: FARC (2 de marzo, 2015). https://www.seman a.com/nacion/articulo/farc-dicen-que-no-pagaran-carcel-en-respuesta-declaraciones-de-kofi-annan/419700-3

Semana, Ley de procedimiento de la JEP pasa en el Congreso, pero el último pulso será en la corte (27 de mayo, 2018). ht tps://www.semana.com/nacion/articulo/ley-de-procedimiento-de-la-jep-fue-aprobada-por-senado/573226

Semana, "Respetamos la soberania de Colombia": Estados Unidos sobre cancelación de visas a magistrados (5 de mayo, 2019). https://www.semana.com/nacion/articulo/embajada-de-estados-unidos-se-pronuncia-sobre-cancelacio n-de-visas-a-magistrados/614417

Senado de Colombia, Senado aprueba procedimiento de la JEP con modificaciones del Centro Democrático (27 de junio, 2018). http://www.senado.gov.co/noticiero-del-senado/item/28132-senado-aprueba-procedimiento-de-la-jep -con-modificaciones-del-centro-democratico

Verdad Abierta, ¿Corte Constitucional dejó a medias la justicia transicional? (2017). https://verdadabierta.com/corteconstitucional-dejo-a-medias-la-justicia-transicional/

\section{Notas}

[1] Pierre Bourdieu, La Fuerza del Derecho. Elementos para una sociología del campo jurídico (Ediciones Uniandes, Instituto Pensar, Siglo del Hombre Editores, 2001).

[2] Íd.

[3] Ruti G. Teitel, Transnational Justice (Oxford University Press, 2000).

[4] Diego Alejandro Martínez, Hacia una ampliación del concepto de justicia. La Jurisdicción Especial para la Paz en Colombia, en La justicia al encuentro de la paz en contextos de transición. Reflexiones actuales para desafíos colombianos (Camilo Eduardo Umaña ed., Universidad Externado de Colombia, 2018). 
[5] Acuerdo Final de Paz [Gobierno Nacional y FARC-EP]. Acuerdo final para la terminación del conflicto y la construcción de una paz estable y duradera. 12 de noviembre de 2016.

[6] Elin Skaar, Jemima García-Godos \& Cath Collins, Transitional Justice in Latin America. The uneven road from impunity towards accountability (Routledge, 2016).

[7] Ver, Comité Internacional de la Cruz Roja (CICR), La situación humanitaria se agravó en 2018 (2019).

[8] Comisión Colombiana de Juristas, El espejismo de la justicia y la paz. Balance sobre la aplicación de la ley 975 de 2005 (2008).

[9] Rodrigo Uprimny \& Maria Paula Saffon, Reparaciones transformadoras, justicia distributiva y profundización democrática, en Reparar en Colombia: los dilemas en contextos de conflicto, pobreza y exclusión (Catalina Díaz, Camilo Sánchez \& Rodrigo Uprimny, eds., Centro de Estudios de Derecho, Justicia y Sociedad, Dejusticia, 2009).

[10] Acuerdo Final de Paz [Gobierno Nacional y FARC-EP], op. cit.

[11] María Isabel Rueda, "Porpoco logramos un acuerdo con Álvaro Uribe": Sergio Jaramillo. Entrevista con María Isabel Rueda, El Tiempo (8 de agosto, 2017).

[12] Ver, Acto Legislativo 01 de 2012, Por medio del cual se establecen instrumentos jurídicos de justicia transicional en el marco del artículo 22 de la Constitución Política y se dictan otras disposiciones, 31 de julio de 2012. D.O. No. 48.508.

[13] Semana, Koffi Annan se equivoca, no vamos a pagar ni un día de cárcel: FARC (2 de marzo, 2015).

[14] Semana, ¿Cómo se cocinó el acuerdo sobre justicia en La Habana? (26 de septiembre, 2015).

[15] Para mayor profundidad ver, Gabriel Ignacio Gómez, Entre el castigo y la reconciliación. Análisis sociojurídico del proceso de paz y la negociación del Acuerdo sobre las Victimas del Conflicto, Revista Estudios Políticos, n. ${ }^{\circ}$ 50, 236-256 (2017); Diego Alejandro Martínez, op. cit.

[16] Francisco De Roux, La audacia de la paz imperfecta (Editorial Planeta, 2018).

[17] Estos sectores, además del gobierno y la coalición que lo respaldaba en el congreso, congregaba a una multiplicidad de actores no gubernamentales, intergubernamentales, medios de comunicación, sectores académicos y sociales de múltiples tendencias políticas, pero que coincidían en la importancia de una salida negociada al conflicto armado.

[18] Esta orientación igualmente articulaba diferentes sectores políticos y sociales, pero en los que se destacaba Álvaro Uribe y su partido, El Centro Democrático. Pero igualmente, en los debates políticos se participaba el partido Conservador, algunos sectores empresariales, medios de comunicación y sectores sociales que desconfiaba de las negociaciones con las FARC, o que no estaba de acuerdo total o parcialmente con el resultado de dichas negociaciones.

[19] Ricardo Monsalve Gaviria, Uribe arremete contra la Jurisdicción Especial de Paz, El Colombiano (17 de Julio, 2016).

[20] La primera versión del Acuerdo Final para la terminación del Conflicto y una Paz Estable y Duradera, se firmó en Cartagena el 30 de septiembre de 2016 en un evento con presencia de representantes de la comunidad internacional.

[21] Sobre una crítica a la democracia liberal ver, Chantal Mouffe, Democracia Política y pluralismo agónico, Revista Derecho y Humanidades. n. ${ }^{\circ}$ 12, 17-27 (2006).

[22] Para mayor profundidad, ver, Sandra Botero, Elplebiscito y los desafíos politicos de consolidar la paz negociada en Colombia, 37 Revista de Ciencia Política, n. ${ }^{\circ}$ 2, 369-388 (2017).

[23] Redacción EL TIEMPO, Polarización del país reflejada en los resultados del escrutinio, El Tiempo (2 de octubre, 2016).

[24] Diario La República, Entrevista con Juan Carlos Vélez, YouTube (5 de octubre, 2016). https://www.youtube.com/wat ch?v=9Jwuk-fGbrs

[25] Íd.

[26] Fundación Ideas para la Paz, Radiografía del plebiscito y el posplebiscito (2016).

[27] María Isabel Rueda, op. cit.

[28] Los cambios principales se hicieron en los puntos 5.1.2. Para mayor profundidad, ver: Gobierno Nacional, Documento de trabajo: cambios, precisiones y ajustes (2016).

[29] María Isabel Rueda, op. cit.

[30] Ver Acto Legislativo 01 de 2016. Por medio del cual se establecen instrumentos jurídicos para facilitar y asegurar la implementación y el desarrollo normativo del Acuerdo Final para la terminación del conflicto y la construcción de una paz estable y duradera, 07 de julio de 2016. D.O. No. 49927.

[31] Colprensa, Gobierno solicita prórroga de aplicación del “fast track”, El País (26 de mayo, 2017).

[32] Redacción Política, Implementación va en 18.3\%, según el Observatorio de Seguimiento al Acuerdo de Paz, El Espectador (4 de enero, 2018).

[33] Los partidos que hacían parte de la Unidad Nacional eran el Partido de la U, el Partido Liberal, el Partido Verde, Cambio Radical y el Polo Democrático (apoyaban al gobierno en cuanto al proceso de paz).

[34] Ver, Acto Legislativo 01 de 2017. Artículo transitorio 7, parágrafo 1. Por medio del cual se crea un título de disposiciones transitorias de la constitución para la terminación del conflicto armado y la construcción de una paz estable y duradera y se dictan otras disposiciones, 4 de abril de 2017. D.O. 50.196.

[35] Colombia 2020, Listos los magistrados. ¿Qué viene para la JEP?, El Espectador (26 de septiembre, 2017).

[36] Cambio Radical, Cambio Radical no votará reglamentación de la Jurisdicción Especial para la Paz (2017). 
[37] Redacción Política, Organizaciones sociales rechazan impedimentos a magistrados de la JEP, El Espectador (16 de noviembre, 2017).

[38] Comisión Interamericana De Derechos Humanos (CIDH), Informe Anual. Capítulo V. Seguimiento de recomendaciones formuladas por la CIDH en sus informes de país o temáticos (2017).

[39] Ministerio de Justicia, Congreso aprueba el Proyecto de Ley Estatutaria de la administración de justicia en la Jurisdicción Especial para la Paz (JEP) (30 de noviembre, 2017).

[40] Ver, por ejemplo, Nelson Camilo Sánchez, Leigh Payne, Gabriel Pereira, Laura Bernal, Daniel López \& Miguel Barboza, Cuentas claras. El papel de la Comisión de la Verdad en la develación de la responsabilidad de empresas en el conflicto armado colombiano (Dejusticia, 2018).

[41] Centro Democrático, "Proyecto de ley estatutaria de JEP es irregular": Centro Democrático, YouTube (12 de noviembre, 2017).

[42] Cambio Radical, op. cit.

[43] Senado de Colombia, Senado aprueba procedimiento de la JEP con modificaciones del Centro Democrático (27 de junio, 2018).

[44] Justicia, Capturan por narcotráfico a Jesús Santrich, por petición de EEUU, El Tiempo (9 de abril, 2018).

[45] RCN Radio, Duque advierte que extraditará a Jesús Santrich si delinquió después de proceso de paz (29 de mayo, 2018).

[46] Redacción Judicial, La Fiscalía captura a alias "Jesús Santrich", El Espectador (9 de abril, 2018).

[47] Redacción Judicial, JEP pide a la Fiscalía expediente completo de Jesús Santrich, El Espectador (18 de septiembre, 2018).

[48] Semana, Ley de procedimiento de la JEP pasa en el Congreso, pero el último pulso será en la corte (27 de mayo, 2018).

[49] Rodrigo Uprimny, Extradición, victimas y paz: el caso “Santrich”, Dejusticia (5 de mayo, 2018).

[50] Dejusticia, Dejusticia y la Comisión Colombiana de Juristas demandan la ley de procedimiento de la JEP (2 de agosto, 2018).

[51] Corte Constitucional de Colombia. Sentencia C-080 de 2018 (M.P. Antonio José Lizarazo; 15 de agosto de 2018).

[52] Íd.

[53] Colombia 2020, Listos los magistrados... op. cit.; y Cambio Radical, op. cit.

[54] Esta modificación se introdujo cuando se conoció el comunicado de la Corte Constitucional No. 55, que hacía referencia a la sentencia sobre el Acto Legislativo 01 de 2017. Al respecto, ver, Verdad Abierta, ¿Corte Constitucional dejó a medias la justicia transicional? (2017).

[55] Corte Constitucional de Colombia. Sentencia C-080 de 2018 (M.P. Antonio José Lizarazo; 15 de agosto de 2018).

[56] Ricardo Monsalve Gaviria, op. cit.

[57] Corte Constitucional de Colombia. Sentencia C-080 de 2018 (M.P. Antonio José Lizarazo; 15 de agosto de 2018).

[58] Íd., párr. 4.1.6.1.

[59] Corte Constitucional de Colombia. Sentencia C-112 (M. P. José Fernando Reyes Cuartas; 13 de marzo de 2019).

[60] Íd.

[61] Íd.

[62] Presidencia de la República de Colombia, Alocución del presidente Iván Duque sobre la Ley Estatutaria de la Jurisdicción Especial para la Paz (2019).

[63] La Silla Vacía, Goebertus vs. Duque objeciones JEP, YouTube (13 de marzo, 2019).

[64] Justicia, Corte decide no pronunciarse sobre las objeciones de Duque a la JEP, El Tiempo (21 de marzo, 2019).

[65] Semana, "Respetamos la soberanía de Colombia": Estados Unidos sobre cancelación de visas a magistrados (5 de mayo, 2019).

[66] Política, Uribismo arremete contra la JEP tras decisión que favorece a Santrich, El Tiempo (15 de mayo, 2019).

[67] Semana, Corte Suprema ordena libertad de Jesús Santrich (29 de mayo, 2019).

[68] Redacción Política, Acato la decisión de la Corte: Presidente Duque, obligado a sancionar la ley estatutaria de la JEP, El Espectador (29 de mayo, 2019).

* Artículo de investigación

\section{Licencia Creative Commons CC BY 4.0}

Cómo citar este artículo: Gabriel Ignacio Gómez, Las disputas por la Jurisdicción Especial para la Paz (JEP): una reflexión critica sobre su sentido politico y juridico, 69 Vniversitas (2020). https://doi.org/10.11144/Jav eriana.vj69.djep 